\title{
Erratum to: Vegetation Placement for Summer Built Surface Temperature Moderation in an Urban Microclimate
}

\author{
Andrew A. Millward · Melissa Torchia • \\ Andrew E. Laursen · Lorne D. Rothman
}

Published online: 19 April 2014

(c) Springer Science+Business Media New York 2014

\section{Erratum to: Environmental Management \\ DOI 10.1007/s00267-014-0260-8}

The first sentence in the "Acknowledgments" section is incorrect. It should be read as "Comments provided by three anonymous reviewers helped to improve an earlier version of this manuscript" instead of "We would like to acknowledge three anonymous reviewers for their comments helped to improve an earlier version of this manuscript."

Hence, the correct version of acknowledgements section is presented below.

Acknowledgments Comments provided by three anonymous reviewers helped to improve an earlier version of this manuscript. Financial assistance from Ryerson University's Environmental Applied Science and Management Program

The online version of the original article can be found under doi:10.1007/s00267-014-0260-8.

A. A. Millward ( $₫)$

Urban Forest Research \& Ecological Disturbance (UFRED)

Group, Department of Geography, Ryerson University, Toronto,

ON M5B 2K3, Canada

e-mail: millward@ryerson.ca

M. Torchia

Environmental Applied Science and Management, Ryerson

University, Toronto, ON, Canada

A. E. Laursen

Department of Chemistry and Biology, Ryerson University,

Toronto, ON, Canada

L. D. Rothman

SAS Institute (Canada) Inc., 280 King Street East, Toronto,

ON M5A 1K7, Canada supported the purchase of equipment. Preparation of this manuscript was aided with a grant provided by the office of the Dean of Arts, Ryerson University. Anna Bowen gave editorial assistance during the writing of this manuscript. 